\title{
Energy security in Bangladesh perspective—an assessment and implication
}

\begin{abstract}
Energy is a key indicator of the nation's overall economic as well as social development. Looking at the present energy demand scenario in Bangladesh, electricity demand has significantly increased over the past years. Most of the Bangladesh's power plants are heavily dependent on expensive imported fossil fuel energy resources. Thus, the power failure has become an acute problem for the country and adversely affects the socio-economic development of the country. Consequently, the shortage and constraint in availability of fossil fuels appeal to boost up the renewable energy sector in Bangladesh in order to bring down the gap between demand and supply. Hence, decisive steps to reform the power sector with a mandate to oversee these sectors urgently need to overcome current energy crisis facing in the country. In this paper, efforts have been made to summarize the availability, current status, strategies, perspectives, promotion policies, major achievements and future potential of energy options in Bangladesh.
\end{abstract}

Keyword: Energy; Fossil fuel; Power sector; Energy crisis; Renewable energy 